\title{
The APOE $\varepsilon 4$ Allele Is Associated with Incident Mild Cognitive Impairment among Community-Dwelling Older Persons
}

\author{
Patricia A. Boyle ${ }^{a, d}$ Aron S. Buchman ${ }^{b, d}$ Robert S. Wilson ${ }^{a, b, d}$ \\ Jeremiah F. Kelly ${ }^{c, d}$ David A. Bennett ${ }^{b, d}$ \\ Departments of a Behavioral Sciences, ${ }^{\mathrm{b}}$ Neurological Sciences and $\mathrm{C}$ Internal Medicine, and \\ ${ }^{\mathrm{d}}$ Rush Alzheimer's Disease Center, Rush University Medical Center, Chicago, III., USA
}

\section{Key Words}

Apolipoprotein E · Mild cognitive impairment · Aging •

Alzheimer's disease, preclinical

\begin{abstract}
Background: The apolipoprotein E (APOE) $\varepsilon 4$ allele is a wellknown risk factor for the development of Alzheimer's disease, but little is known about the association of the $\varepsilon 4$ allele with incident mild cognitive impairment $(\mathrm{MCl})$. Objective: Test the hypothesis that the $\varepsilon 4$ allele is associated with an increased risk of developing $\mathrm{MCl}$. Methods: More than 600 older Catholic clergy members from the Religious Orders Study without any cognitive impairment at baseline underwent APOE genotyping and detailed annual clinical evaluations for up to 16 years of follow-up (mean: 10.17 years; range: 2-16 years) to document incident $\mathrm{MCl}$ and rates of decline in global cognition and 5 cognitive domains (i.e. episodic memory, semantic memory, working memory, perceptual speed and visuospatial abilities). Results: During up to 16 years of annual follow-up, 339 of 607 persons (56\%) developed $\mathrm{MCl}$. In a proportional hazards model adjusted for age, sex and education, the presence of the APOE $\varepsilon 4$ allele was associated with a 1.4-fold increased risk of incident MCI (hazard ratio: $1.36 ; 95 \% \mathrm{Cl}: 1.04,1.78)$. Further, this association persisted in analyses that required $\mathrm{MCl}$ to persist for at least
\end{abstract}

one year (hazard ratio: 1.50; $95 \% \mathrm{Cl}: 1.05,2.14$ ). Finally, the $\varepsilon 4$ allele was associated with an increased rate of decline in global cognition and 4 out of 5 cognitive systems (i.e. episodic memory, semantic memory, working memory and perceptual speed). Conclusion: The presence of the APOE $\varepsilon 4$ allele is associated with an increased risk of $\mathrm{MCl}$ and a more rapid rate of cognitive decline in old age.

Copyright $\odot 2009$ S. Karger AG, Basel

\section{Introduction}

Accumulating evidence suggests that mild cognitive impairment (MCI) is the precursor to dementia, particularly Alzheimer's disease (AD) [1-3]. MCI is associated with a substantially increased risk of developing $\mathrm{AD}$ and with a more rapid rate of cognitive decline, and most persons with MCI exhibit the pathologic hallmarks of $\mathrm{AD}$ at autopsy [4-9]. The recognition of MCI as the earliest clinical manifestation of $\mathrm{AD}$ has generated interest in identifying the factors associated with its development. However, relatively few such factors have been identified [1014]. This is in part because MCI develops gradually over many years, and longitudinal studies of large groups of older persons initially free of cognitive impairment are needed to identify risk factors. Knowledge of the factors

\section{KARGER}

(C) 2009 S. Karger AG, Basel

Fax +41613061234

E-Mail karger@karger.ch

www.karger.com
Accessible online at:

www.karger.com/ned
Patricia Boyle, $\mathrm{PhD}$

Rush Alzheimer's Disease Center, Rush University Medical Center

Armour Academic Facility, Suite 1020B

600 South Paulina Street, Chicago, IL 60612 (USA)

Tel. +1 312942 8749, Fax +1 312563 4604, E-Mail Patricia_Boyle@ rush.edu 
associated with MCI is necessary for the effort to develop disease-modifying therapies for $\mathrm{AD}$ and, ultimately, for the prevention of cognitive decline in old age.

The apolipoprotein $\mathrm{E}$ (APOE) $\varepsilon 4$ allele is a well-established risk factor for the development of $\mathrm{AD}$, with the association reported in this and other cohorts [15-19]. Data from recent studies provide evidence that the $\varepsilon 4$ allele is also associated with an increased risk of conversion from MCI to dementia, and cross-sectional findings suggest that the $\varepsilon 4$ allele is associated with the level of cognitive impairment among persons with MCI [20-22]. Although these findings suggest that the $\varepsilon 4$ allele is likely to be a potent risk factor for MCI, few studies have carefully excluded persons with even MCI at baseline to examine the association of the $\varepsilon 4$ allele with the risk of MCI [23-25]. Further, the relation of the $\varepsilon 4$ allele to the rate of change in cognitive function among older persons without dementia or MCI remains unknown.

In this study, we tested the hypothesis that the presence of the APOE $\varepsilon 4$ allele is associated with an increased risk of incident MCI, using data from more than 600 participants in a large epidemiologic study of aging, the Religious Orders Study [4, 7]. In subsequent analyses, we examined whether this association persisted in an analysis requiring MCI to persist for at least 1 year. Finally, we examined the association of the $\varepsilon 4$ allele with the rate of change in cognitive function among older persons.

\section{Method}

\section{Participants}

The participants were older Catholic clergy members from the Religious Orders Study, a longitudinal clinicopathologic study of common chronic conditions of old age $[4,7]$. The participants came from more than 40 groups across the USA. As a condition of entry, all the participants agreed to annual detailed clinical evaluations and brain donation at the time of death. The study was in accordance with the latest version of the Declaration of Helsinki and was approved by the Institutional Review Board of the Rush University Medical Center.

The participants of the Religious Orders Study underwent a uniform structured clinical evaluation at baseline. This evaluation included a medical history, a neurological and physical examination, and an assessment of cognitive function. Follow-up clinical evaluations were identical in all essential details to the baseline examination and were performed at 1-year intervals by examiners blinded to previously collected data. At the time of these analyses, 1,126 participants had completed the baseline evaluation. Eligibility for these analyses required the absence of clinical dementia or MCI at baseline, based on detailed cognitive function testing (see below) and valid genotype data. In addition, because prior studies have shown that the $\varepsilon 2$ allele is protective against cognitive decline, persons with the $\varepsilon 2 / 4$ genotype were excluded. Thus, 79 persons who met criteria for dementia at the baseline evaluation, 273 persons who met criteria for MCI, 125 without valid genotyping, 14 with the $\varepsilon 2 / 4$ genotype, 18 who died before the first follow-up, and 10 who had only 1 evaluation were excluded. This resulted in a final group of 607 persons included in these analyses. They had an average of 10.17 follow-up evaluations (SD: 3.91 ; range: $2-16$ ), and $>94 \%$ had $>2$ follow-up evaluations. Their mean age was 74.16 years (SD: 6.45 years; range: $62-$ 95 years), mean education 18.08 years (SD: 3.48 years; range: $3-30$ years), mean MMSE (Mini-Mental State Examination) [26] score 28.81 (SD: 1.45; range: 19-30) and mean global cognitive function score 0.24 (SD: 0.45 ; range: -1.58 to 1.49 ); $68 \%$ were women and $93 \%$ white and non-Hispanic.

\section{Assessment of Cognitive Function}

Cognitive function was assessed via a battery of 20 tests, as previously described [5-7]. This battery included the MMSE [21], but MMSE scores are used only to describe the cohort. Scores on the remaining 19 tests were used to create summary indices of global cognitive function and 5 specific cognitive domains: episodic memory, semantic memory, working memory, perceptual speed and visuospatial ability. Measures used to assess the domains were as follows: (1) episodic memory: immediate and delayed recall of story A from Logical Memory and the East Boston Story, as well as Word List Memory, Recall and Recognition from the Consortium to Establish a Registry for AD neuropsychological battery; (2) semantic memory: the 20-item version of the Boston Naming Test, Verbal Fluency, 15 -item reading test and 20-item version of the National Adult Reading Test; (3) working memory: the Digit Span Forward and Backward, Digit Ordering, and Alpha Span Tests; (4) perceptual speed: the Symbol Digit Modalities Test, Oral Version, and the Number Comparison Test, and (5) visuospatial abilities: the 15-item version of Judgment of Line Orientation and the 17-item version of the Standard Progressive Matrices.

To compute the composite measure of global cognitive function, raw scores on each of the individual tests were converted to $\mathrm{z}$ scores, using the baseline mean and SD of the entire cohort, and the $\mathrm{z}$ scores of all 19 tests were averaged [5-7]. In addition, summary scores for 5 cognitive domains (i.e. episodic memory, semantic memory, working memory, perceptual speed and visuospatial abilities) were derived by converting raw scores on each of the individual tests to $\mathrm{z}$ scores, using the mean and SD of the entire cohort, and then averaging the $\mathrm{z}$ scores from tests within a specific domain. Psychometric information on these summary scores, including factor-analytic support for the 5 domains, is contained in previous publications [5-7].

\section{Clinical Diagnoses}

All participants underwent uniform structured clinical evaluations including a medical history, neurologic examination and cognitive performance testing, as previously described [4, 7]. The cognitive tests were reviewed by an experienced neuropsychologist. The participants were evaluated in person by a physician, who used all available cognitive and clinical testing results from the current evaluation, to diagnose dementia and other common neurologic conditions affecting cognitive function. The diagnoses of dementia and MCI were made by clinicians blinded to the APOE genotyping of the participants. The diagnosis of dementia followed the criteria of the joint working group of the National Institute of Neurological and Communicative Disorders and 
Stroke and the AD and Related Disorders Association [27]. These require a history of cognitive decline and evidence of impairment in 2 or more domains of cognition, one of which must be memory for classification as AD. Persons were diagnosed with MCI if they were determined to have cognitive impairment by the neuropsychologist but did not meet criteria for dementia, as previously described [5-7]. Although no consensus criteria have been established for MCI, these criteria are similar to those proposed by others [24] and have been validated in this and other cohorts in studies showing associations with subsequent development of dementia, cognitive decline and AD pathology [5-7, 28, 29].

\section{APOE Genotyping}

Blood was collected at each study site, using BD Vacutainer CPT cell preparation tubes containing sodium citrate and stored at room temperature. The mononuclear cell layer was isolated within $24 \mathrm{~h}$ of collection. DNA was extracted from approximately 2-3 million mononuclear cells using Flexigene DNA extraction kits (Qiagen, Valencia, Calif., USA), and quantified in 96-well plates using Quant-iT ${ }^{\text {TM }}$ PicoGreen ${ }^{\circledR}$ dsDNA detection assay kits (Molecular Probes, Eugene, Oreg., USA). Genotyping was performed at the Agencourt Bioscience Corporation (Beverly, Mass., USA), utilizing high-throughput sequencing of codon 112 (position 3937) and codon 158 (position 4075) of exon 4 of the APOE gene on chromosome 19 by an investigator blinded to all clinical and postmortem data, as previously described [30].

Participants with 1 or more copies of the $\varepsilon 4$ allele [i.e. $\varepsilon 3 / 4$ $(\mathrm{n}=124)$ and $\varepsilon 4 / 4(\mathrm{n}=7)]$ were considered positive for $\varepsilon 4$ for these analyses. All other participants with other allele combinations [i.e. $\varepsilon 2 / 2(n=2), \varepsilon 2 / 3(n=77)$ or $\varepsilon 3 / 3(n=397)$ ] were considered negative for $\varepsilon 4$.

\section{Comorbidities and Other Covariates}

Gender, race and age were recorded at baseline. Gender was coded as ' 1 ' for men, ' 0 ' for women. The race questions and categories were those used by the 1990 US Census. Age in years was computed from the self-reported date of birth and the date of the clinical examination.

Education (reported highest grade or years of education) was obtained at baseline.

\section{Statistical Analyses}

For all analyses, the participants were divided into those with 1 or more $\varepsilon 4$ alleles (i.e. $\varepsilon 3 / 4$ or $4 / 4$ ) and those without an $\varepsilon 4$ allele (i.e. $\varepsilon 2 / 2,2 / 3$ and $3 / 3$ ). Pearson correlations were used to examine the associations of the APOE $\varepsilon 4$ allele with age and education. Student's t tests, Wilcoxon's rank-sum tests or $\chi^{2}$ tests were used to compare measures among those who did and did not develop MCI. Proportional hazards models for discrete (tied) data were used to examine the association of the APOE $\varepsilon 4$ allele with incident MCI [31]; all models were adjusted for age, sex and education. The first occurrence of MCI was used as the outcome in the initial series of models, and we then conducted models requiring MCI to have persisted for at least 1 year (i.e. MCI followed by MCI, dementia or death). In subsequent models, we tested for interactions of the APOE $\varepsilon 4$ allele with age, sex and education. Finally, we conducted mixed-effect models to examine the association of the $\varepsilon 4$ allele with the rate of cognitive decline [32]. The models were examined graphically and analytically, and assumptions judged to be adequately met. Programming was done in SAS ${ }^{\circledR}[33]$.
Table 1. Baseline characteristics of participants who developed MCI versus those who did not

\begin{tabular}{lllr}
\hline & $\begin{array}{l}\text { Did not de- Developed } \\
\text { velop MCI }\end{array}$ & MCI \\
& & \\
\hline Age, years & $71.9 \pm 5.50$ & $75.9 \pm 6.61$ & $<0.001$ \\
Female gender, \% & 69.0 & 67.6 & 0.699 \\
Race white and non-Hispanic, \% & 93.7 & 93.2 & 0.820 \\
Education, years & $18.1 \pm 3.54$ & $18.0 \pm 3.43$ & 0.770 \\
Global cognitive function score & $0.40 \pm 0.43$ & $0.11 \pm 0.42$ & $<0.001$ \\
APOE 8 4 allele, \% & 19.4 & 23.3 & 0.246 \\
MMSE score & $29.3 \pm 1.01$ & $28.5 \pm 1.64$ & $<0.001$
\end{tabular}

Values denote means \pm SD unless otherwise noted. Statistical significance is based on t tests, Wilcoxon's rank-sum tests or $\chi^{2}$ tests, as appropriate.

\section{Results}

Association of APOE $\varepsilon 4$ Allele with Incident $\mathrm{MCI}$

The distribution of the APOE genotypes in the study participants was as follows: $\varepsilon 2 / 2=2, \varepsilon 2 / 3=77, \varepsilon 3 / 3=397$, $\varepsilon 3 / 4=124$ and $\varepsilon 4 / 4=7$. During up to 16 years of followup (mean: 10.7 years; SD: 3.91 years; range: 2-16 years), 339 persons (56\% of 607 ) developed MCI. Persons who developed MCI were older and had lower cognition at baseline compared to those who did not develop MCI (table 1).

In a proportional hazards model adjusted for age, sex and education, the presence of the APOE $\varepsilon 4$ allele was associated with an increased risk of MCI (hazard ratio: 1.36; 95\% CI: 1.04, 1.78). Figure 1 illustrates that a person with the $\varepsilon 4$ allele had an about 1.4-fold greater risk of developing MCI compared to a person without the $\varepsilon 4$ allele.

Next, because MCI does not uniformly progress to dementia or persist [1-5], we constructed a proportional hazards model to examine the association of the $\varepsilon 4$ allele with persistent MCI (meaning that MCI was present on consecutive examinations or followed by dementia or death). Of 339 persons with incident $\mathrm{MCI}$ in the analyses described above, 184 had persistent MCI; those without persistent MCI were included in the reference group. In this analysis, the risk of MCI was increased among persons with the $\varepsilon 4$ allele (hazard ratio: 1.50 ; $95 \%$ CI: 1.05 , 2.14). Thus, these findings were similar to the results above and suggest that they were not influenced by diagnostic misclassification. 


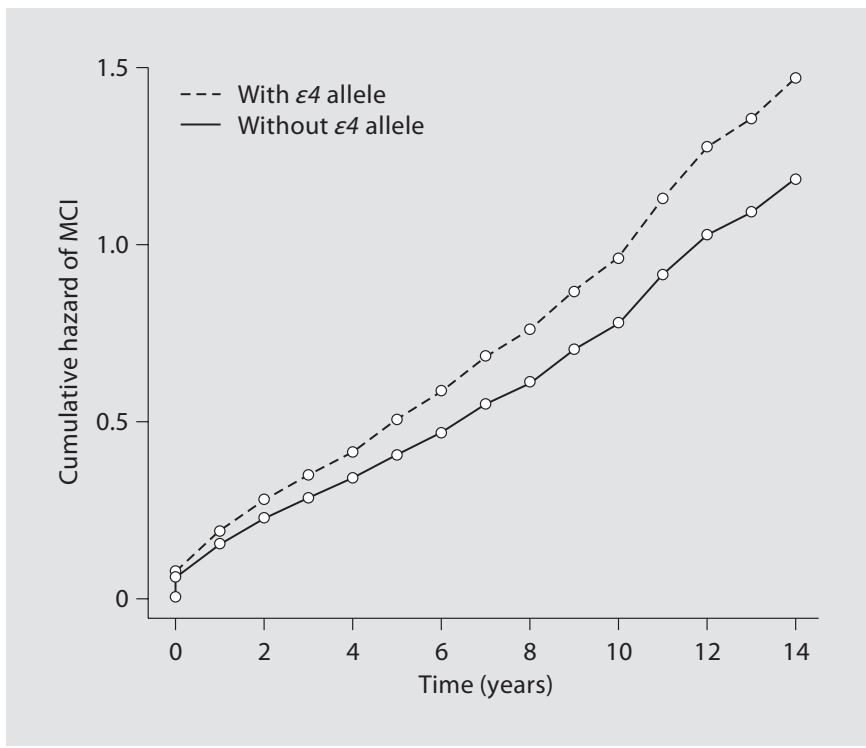

Fig. 1. Association of the APOE $\varepsilon 4$ allele with the risk of MCI for a typical participant with versus without the $\varepsilon 4$ allele, derived from a proportional hazards model adjusted for age, sex and education.

Table 2. Relation of the $\varepsilon 4$ allele to the rate of change in cognitive function

\begin{tabular}{llrr}
\hline & Model term & Estimate (SE) & \multicolumn{1}{c}{$\mathrm{p}$} \\
\hline Global cognition & APOE $\varepsilon 4$ & $0.016(0.036)$ & 0.655 \\
& APOE $\varepsilon 4 \times$ time & $-0.045(0.009)$ & $<0.001$ \\
Episodic memory & APOE $\varepsilon 4$ & $-0.019(0.042)$ & 0.659 \\
& APOE $\varepsilon 4 \times$ time & $-0.054(0.013)$ & $<0.001$ \\
Semantic memory & APOE $\varepsilon 4$ & $0.068(0.050)$ & 0.177 \\
& APOE $\varepsilon 4 \times$ time & $-0.043(0.009)$ & $<0.001$ \\
Working memory & APOE $\varepsilon 4$ & $0.073(0.055)$ & 0.187 \\
& APOE $\varepsilon 4 \times$ time & $-0.028(0.006)$ & $<0.001$ \\
Perceptual speed & APOE $\varepsilon 4$ & $-0.031(0.068)$ & 0.653 \\
& APOE $\varepsilon 4 \times$ time & $-0.024(0.010)$ & 0.017 \\
Visuospatial ability & APOE $\varepsilon 4$ & $-0.048(0.055)$ & 0.384 \\
& APOE $\varepsilon 4 \times$ time & $-0.011(0.007)$ & 0.111 \\
\hline & & &
\end{tabular}

Derived from models that included terms for age, sex, education, time, time squared and the interactions of the demographic variables with time.

In subsequent models, we repeated the models described above with additional terms to test for interactions of the $\varepsilon 4$ allele with age, sex and education. The association of the $\varepsilon 4$ allele with MCI was not influenced by demographic characteristics (data not shown).

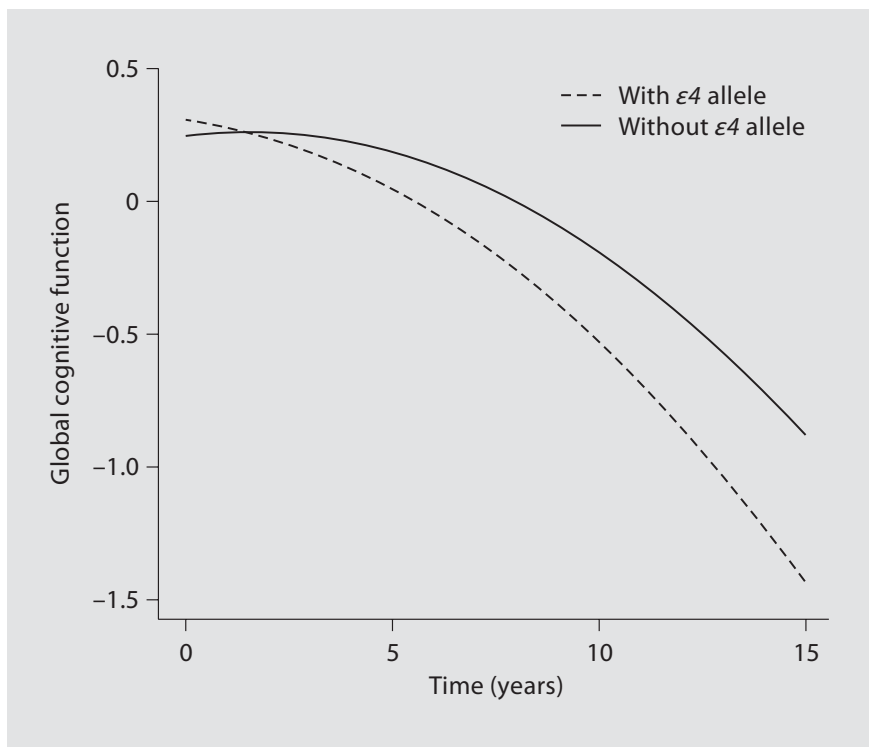

Fig. 2. Association of the APOE $\varepsilon 4$ allele with the rate of change in global cognition for a typical participant with versus without the $\varepsilon 4$ allele, derived from a proportional hazards model adjusted for age, sex and education.

\section{$\varepsilon 4$ Allele and Rate of Cognitive Decline}

Because the principal manifestation of MCI is cognitive impairment that develops slowly over time, to further evaluate the robustness of the association of the $\varepsilon 4$ allele with MCI, we examined the relation of the $\varepsilon 4$ allele to the rate of change in cognitive function in a series of mixed-effect models controlled for age, sex and education. In the first model, which controlled for the baseline level of cognition, the presence of the $\varepsilon 4$ allele was associated with a more rapid rate of decline in global cognition, as indicated by the term for $\varepsilon 4 \times$ time (table 2; fig. 2). Additional models examined 5 separate cognitive abilities, starting with episodic memory, the hallmark of $\mathrm{AD}$, and 4 other measures including semantic memory, working memory, perceptual speed and visuospatial ability (table 2). The $\varepsilon 4$ allele was associated with a more rapid rate of decline in 4 of the 5 systems, with its strongest effect on episodic memory.

\section{Discussion}

In a cohort of more than 600 well-characterized older persons free of cognitive impairment at baseline and with up to 16 years of annual follow-up, we found that the presence of the $\varepsilon 4$ allele was associated with an increased risk 
of developing MCI, whether defined as the first occurrence of or persistent MCI. This association did not vary along demographic lines. Further, the $\varepsilon 4$ allele was associated with an increased rate of decline in global cognition and 4 out of 5 specific cognitive systems, with its strongest effect on episodic memory. Thus, the $\varepsilon 4$ allele is associated with an increased risk of developing MCI and may be a useful marker for identifying persons at high risk for the very earliest manifestation of cognitive impairment.

Awareness of MCI as the prodromal stage of AD has shifted the field of cognitive aging research from a focus on identifying persons at risk of dementia to those at risk of the earliest manifestation of cognitive impairment who may be most amenable to treatment. Importantly, however, relatively few risk factors for MCI have been identified [10-14, 34]. MCI develops slowly over time, and incidence studies require large samples of persons without cognitive impairment on whom data from multiple years of observation are available. Further, there remains debate regarding the appropriate classification of MCI. The MCI criteria used in this study have been used in many previously published studies and have been shown in this and other cohorts to be predictive of an increased risk of $\mathrm{AD}$, an accelerated rate of cognitive decline, and AD pathology $[4-7,28,29]$. Nevertheless, because $\mathrm{MCI}$ is not always a stable condition, we examined the association of the APOE $\varepsilon 4$ allele with MCI defined on the basis of its first occurrence and persistent MCI (meaning it was present for 2 or more years or followed by dementia or death), as well as the association of the $\varepsilon 4$ allele with the rate of change in cognitive function.

Little data are available on the association of the APOE $\varepsilon 4$ allele with the risk of incident MCI. Prior studies have shown that the $\varepsilon 4$ allele is associated with an increased rate of conversion from $\mathrm{MCI}$ to $\mathrm{AD}$, with the level of cognitive function among those with MCI, and with an increased likelihood of one-step transitions into amnestic MCI but not multidomain MCI [20-25]. Further, one study of APOE $\varepsilon 4$ carriers in their 60s showed that they exhibited measurable cognitive decline before the onset of MCI or $\mathrm{AD}$, but the study did not have sufficient data to prospectively relate the presence of the APOE $\varepsilon 4$ allele with the risk of developing MCI [35]. That the $\varepsilon 4$ allele predicts incident $\mathrm{MCI}$ and the rate of cognitive decline in older persons (mean age in this study: 74 years) without MCI or AD has important public health implications, particularly with regard to the development of strategies to maintain cognitive health in older persons. MCI represents the transition state between normality and de- mentia and is likely to be much more common than $\mathrm{AD}$ [36]. By the time older persons meet criteria for MCI, they have already exhibited measurable cognitive decline, the hallmark of $\mathrm{AD}$, and most have accumulated the neuropathologic hallmarks of AD [3-7]. Thus, the development of effective treatments to prevent or delay dementia requires the identification of individuals prior to the onset of MCI or AD. The current study extends prior work, and our findings suggest that APOE $\varepsilon 4$ is a risk factor for the very earliest manifestation of cognitive impairment. Further work is needed to document other risk factors for MCI and to examine its underlying biology.

There are several potential biologic bases underlying the link between APOE $\varepsilon 4$, MCI and AD. First, AD pathology is widespread in persons with MCI and even in some without any cognitive impairment, and recent evidence suggests that the APOE $\varepsilon 4$ allele contributes to cognitive impairment via its effect on AD pathology [5, $7,37]$. That is, the $\varepsilon 4$ allele is related to AD pathology identified histopathologically, as well as to molecularly specific markers of amyloid and tau-positive tangles [37, 38]. Moreover, data from our group suggest that amyloid mediates both the association of the $\varepsilon 4$ allele with the level of cognitive function proximate to death and the association of tangles with the level of cognitive function $[37,38]$. By contrast, tangles do not account for the association of the $\varepsilon 4$ allele with amyloid. These data suggest a causal sequence via which the $\varepsilon 4$ allele works first through amyloid deposition and then tangle formation to result in cognitive impairment [37]. Vascular disease is a second potential biologic basis of the association between APOE $\varepsilon 4$ and cognition. Data from this cohort have shown that the $\varepsilon 4$ allele increases the risk of cerebral infarction detected at autopsy, and findings from other studies suggest that the $\varepsilon 4$ allele is associated with the risk of clinical stroke [39]. Importantly, most older persons with cognitive impairment have multiple pathologies [40], and it is likely that APOE $\varepsilon 4$ works through several mechanisms to cause cognitive impairment.

This study has some limitations, including the selected nature of the cohort, and the need to exclude persons with cognitive impairment (i.e. dementia and MCI) at baseline as well as those who had not yet had follow-up visits. In addition, the participants were from a study that requires older persons to agree to organ donation at death, thereby introducing a selection bias. Both of these factors may influence the generalizability of our findings. Finally, cognition was assessed annually, and it is possible that more dense data collection (e.g. every 6 months, as is often done in clinical trials) might have provided more pre- 
cise estimates of the association between APOE and MCI. However, several factors lend confidence to the findings. First, we used 2 definitions of MCI (first occurrence and persistent) to clarify the association of the $\varepsilon 4$ allele with the risk of cognitive impairment, and we examined the association of $\varepsilon 4$ with the rate of cognitive decline using detailed cognitive function testing from evenly spaced evaluations with high rates of annual follow-up. Second, given the large sample size, we were able to address the influence of confounding variables such as age, sex and education in the analyses. Finally, uniform structured procedures were followed, and all personnel collecting genetic and clinical data were blinded to all other data, thereby reducing the potential for bias.

\section{Acknowledgments}

This research was supported by National Institute on Aging grants K23AG23040, R01AG17917 and R01AG24480, the Illinois Department of Public Health and the Robert C. Borwell Endowment Fund.

\section{References}

1 Larrieu S, Letenneur L, Orgogozo JM, et al: Incidence and outcome of mild cognitive impairment in a population-based prospective cohort. Neurology 2002;59:1594-1599.

-2 Fisk JD, Merry HR, Rockwood K: Variations in case definition affect prevalence but not outcomes of mild cognitive impairment. Neurology 2003;61:1179-1184.

3 Morris JC: Mild cognitive impairment is early-stage Alzheimer disease. Arch Neurol 2006;63:15-16.

44 Bennett DA, Wilson RS, Schneider JA, et al: Natural history of mild cognitive impairment in older persons. Neurology 2002;59: 198-205.

5 Boyle PA, Wilson RS, Aggarwal NT, Tang Y, Bennett DA: Mild cognitive impairment: risk of Alzheimer disease and rate of cognitive decline. Neurology 2006;67:441-445.

6 6 Bennett DA, Schneider JA, Bienias JL, Evans DA, Wilson RS: Mild cognitive impairment is related to Alzheimer disease pathology and cerebral infarctions. Neurology 2005; 64:834-841.

7 Bennett DA, Schneider JA, Arvanitakis Z, Kelly JF, Aggarwal NT, Shah RC, Wilson RS: Neuropathology of older persons without cognitive impairment from two communitybased studies. Neurology 2006;66:18371844.

8 Markesbery WR, Schmitt FA, Kryscio RJ, Davis DG, Smith CD, Wekstein DR: Neuropathologic substrate of mild cognitive impairment. Arch Neurol 2006;63:38-46.

$\checkmark 9$ Riley KP, Snowdon DA, Markesbery WR: Alzheimer's neurofibrillary pathology and the spectrum of cognitive function: findings from the Nun Study. Ann Neurol 2002;51: 567-577.

$\checkmark 10$ Reitz C, Tang MX, Manly J, Mayeux R, Luchsinger JA: Hypertension and the risk of mild cognitive impairment. Arch Neurol 2007;64:1734-1740.
11 Solfrizzi V, Panza F, Colacicco AM, D’Introno A, Capurso C, Torres F, Grigoletto F, Maggi S, del Parigi A, Reiman EM, Caselli RJ, Scafato E, Farchi G, Capurso A, Italian Longitudinal Study on Aging Working Group: Vascular risk factors, incidence of MCI, and rates of progression to dementia. Neurology 2004;63:1882-1891.

12 Geda YE, Knopman DS, Mrazek DA, Jicha GA, Smith GE, Negash S, Boeve BF, Ivnik RJ, Petersen RC, Pankratz VS, Rocca WA: Depression, apolipoprotein E genotype, and the incidence of mild cognitive impairment: a prospective cohort study. Arch Neurol 2006; 63:435-440.

13 Wilson RS, Schneider JA, Arnold SE, Bienias JL, Bennett DA: Conscientiousness and the incidence of Alzheimer disease and mild cognitive impairment. Arch Gen Psychiatry 2007;64:1204-1212.

14 Wilson RS, Schneider JA, Arnold SE, Tang Y, Boyle PA, Bennett DA: Olfactory identification and incidence of mild cognitive impairment in older age. Arch Gen Psychiatry 2007; 64:802-808.

15 Evans DA, Bennett DA, Wilson RS, Bienias JL, Morris MC, Scherr PA, Hebert LE, Aggarwal N, Beckett LA, Joglekar R, BerryKravis E, Schneider J: Incidence of Alzheimer disease in a biracial urban community: relation to apolipoprotein $\mathrm{E}$ allele status. Arch Neurol 2003;60:185-189.

$\checkmark 16$ Bennett DA, Wilson RS, Schneider JA, Evans DA, Aggarwal NT, Arnold SE, Cochran EJ, Berry-Kravis E, Bienias JL: Apolipoprotein E $\varepsilon 4$ allele, $\mathrm{AD}$ pathology, and the clinical expression of Alzheimer's disease. Neurology 2003;60:246-252.

$\checkmark 17$ Corder EH, Saunders AM, Strittmatter WJ, Schmechel DE, Gaskell PC, Small GW, Roses AD, Haines JL, Pericak-Vance MA: Gene dose of apolipoprotein E type 4 allele and the risk of Alzheimer's disease in late onset families. Science 1993;261:921-923.
18 Evans DA, Beckett LA, Field TS, Feng L, Albert MS, Bennett DA, Tycko B, Mayeux R: Apolipoprotein E $\varepsilon 4$ and incidence of Alzheimer disease in a community population of older persons. JAMA 1997;277:822-824.

19 Wilson RS, Schneider JA, Barnes LL, Beckett LA, Aggarwal NT, Cochran EJ, Berry-Kravis E, Bach J, Fox JH, Evans DA, Bennett DA: The apolipoprotein $\mathrm{E} \varepsilon 4$ allele and decline in different cognitive systems during a 6-year period. Arch Neurol 2002;59:1154-1160.

20 Aggarwal NT, Wilson RS, Beck TL, Bienias JL, Berry-Kravis E, Bennett DA: The apolipoprotein E $\varepsilon 4$ allele and incident Alzheimer's disease in persons with mild cognitive impairment. Neurocase 2005;11:3-7.

21 Mosconi L, Perani D, Sorbi S, Herholz K, Nacmias B, Holthoff V, Salmon E, Baron JC, de Cristofaro MT, Padovani A, Borroni B, Franceschi M, Bracco L, Pupi A: MCI conversion to dementia and the APOE genotype: a prediction study with FDG-PET. Neurology 2004;63:2332-2340.

22 Ramakers IH, Visser PJ, Aalten P, Bekers O, Sleegers K, van Broeckhoven CL, Jolles J, Verhey FR: The association between APOE genotype and memory dysfunction in subjects with mild cognitive impairment is related to age and Alzheimer pathology. Dement Geriatr Cogn Disord 2008;26:101108.

23 Kryscio RJ, Schmitt FA, Salazar JC, Mendiondo MS, Markesbery WR: Risk factors for transitions from normal to mild cognitive impairment and dementia. Neurology 2006; 66:828-832.

-24 Tyas SL, Salazar JC, Snowdon DA, Desrosiers MF, Riley KP, Mendiondo MS, Kryscio RJ: Transitions to mild cognitive impairments, dementia, and death: findings from the Nun Study. Am J Epidemiol 2007;165:1231-1238. 
-25 Caselli RJ, Reiman EM, Locke DE, Hutton ML, Hentz JG, Hoffman-Snyder C, Woodruff BK, Alexander GE, Osborne D: Cognitive domain decline in healthy apolipoprotein $\mathrm{E} \varepsilon 4$ homozygotes before the diagnosis of mild cognitive impairment. Arch Neurol 2007;64:1306-1311.

-26 Folstein M, Folstein S, McHugh P: MiniMental State: a practical method for grading the mental state of patients for the clinician. J Psychiatr Res 1975;12:189-198.

-27 McKhann G, Drachman D, Folstein M, Katzman R, Price D, Stadlan EM: Clinical diagnosis of Alzheimer's disease: report of the NINCDS-ADRDA Work Group under the auspices of Department of Health and Human Services Task Force on Alzheimer's Disease. Neurology 1984;34:939-944.

-28 Tuokko H, Frerichs R, Graham J, Rockwood K, Kristjansson B, Fisk J, Bergman H, Kozma A, McDowell I: Five-year follow-up of cognitive impairment with no dementia. Arch Neurol 2003;60:577-582.

-29 Aggarwal NT, Wilson RS, Beck TL, Bienias JL, Bennett DA: Motor dysfunction in mild cognitive impairment and the risk of incident Alzheimer disease. Arch Neurol 2006; 63:1763-1769.
30 Buchman AS, Boyle PA, Wilson RS, Beck TL, Kelly JF, Bennett DA: Apolipoprotein E $\varepsilon 4$ allele is associated with more rapid motor decline in older persons. Alzheimer Dis Assoc Disord 2009;23:63-69.

31 Cox DR: Regression models and life tables. J R Stat Soc Ser B Methodol 1972;34:187-220.

32 Laird N, Waire J: Random effects models for longitudinal data. Biometrics 1982;38:963974.

33 SAS 9.1.3 Help and Documentation. Cary, SAS Institute Inc., 2000.

34 Tervo S, Kivipelto M, Hänninen T, Vanhanen M, Hallikainen M, Mannermaa A, Soininen $\mathrm{H}$ : Incidence and risk factors for mild cognitive impairment: a populationbased three-year follow-up study of cognitively healthy elderly subjects. Dement Geriatr Cogn Disord 2004;17:196-203.

35 Caselli RJ, Reiman EM, Osborne D, Hentz JG, Baxter LC, Hernandez JL, Alexander GG: Longitudinal changes in cognition and behavior in asymptomatic carriers of the APOE $\varepsilon 4$ allele. Neurology 2004;62:19901995.
36 Plassman BL, Langa KM, Fisher GG, Heeringa SG, Weir DR, Ofstedal MB, Burke JR, Hurd MD, Potter GG, Rodgers WL, Steffens DC, McArdle JJ, Willis RJ, Wallace RB: Prevalence of cognitive impairment without dementia in the United States. Ann Intern Med 2008;148:427-434.

37 Bennett DA, Schneider JA, Wilson RS, Bienias JL, Berry-Kravis E, Arnold SE: Amyloid mediates the association of apolipoprotein $\mathrm{E}$ $\varepsilon 4$ allele to cognitive function in older people. J Neurol Neurosurg Psychiatry 2005;76: 1194-1199.

>38 Bennett DA, Wilson RS, Schneider JA, Evans DA, Aggarwal NT, Arnold SE, Cochran EJ, Berry-Kravis E, Bienias JL: Apolipoprotein E $\varepsilon 4$ allele, $\mathrm{AD}$ pathology, and the clinical expression of Alzheimer's disease. Neurology 2003;60:246-252.

-39 Schneider JA, Bienias JL, Wilson RS, BerryKravis E, Evans DA, Bennett DA: The apolipoprotein $\mathrm{E} \varepsilon 4$ allele increases the odds of chronic cerebral infarction detected at autopsy in older persons. Stroke 2005;36:954959.

40 Schneider JA, Arvanitakis Z, Bang W, Bennett DA: Mixed pathologies account for most dementia cases in community-dwelling older persons. Neurology 2007;69:2197-2204. 